WORKSHOP ON EDUCATIONAL INNOVATION

IN ARCHITECTURE JIDA'17

JORNADES SOBRE INNOVACIÓ

DOCENT EN ARQUITECTURA JIDA'17

ESCUELA TÉCNICA SUPERIOR DE ARQUITECTURA DE SEVILLA 16 Y 17 DE NOVIEMBRE DE 2017 


\section{GILDA}

Organiza e impulsa GILDA (Grupo para la Innovación y Logística Docente en la Arquitectura), en el marco del proyecto RIMA (Investigación e Innovación en Metodologías de Aprendizaje), de la Universitat Politècnica de Catalunya - BarcelonaTech (UPC) y el Institut de Ciències de l'Educació (ICE). https://www.upc.edu/rima/ca/grups/gilda

\section{Editores}

Daniel García-Escudero, Berta Bardí i Milà

\section{Revisión de textos}

Rodrigo Carbajal Ballell, Silvana Rodrigues de Oliveira, Jordi Franquesa

\section{Edita}

Iniciativa Digital Politècnica Oficina de Publicacions Acadèmiques Digitals de la UPC

ISBN 978-84-9880-681-6 (UPC)

elSSN 2462-571X

D.L. B 9090-2014

(C) de los textos y las imágenes: los autores

(C) de la presente edición: Iniciativa Digital Politècnica Oficina de Publicacions Acadèmiques Digitals de la UPC 


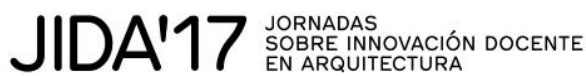

\section{Comité Organizador JIDA'17}

Dirección, coordinación y edición

\section{Berta Bardí i Milà (GILDA)}

Dra. Arquitecta, Departamento de Proyectos Arquitectónicos, ETSAV-UPC

Daniel García-Escudero (GILDA)

Dr. Arquitecto, Departamento de Proyectos Arquitectónicos, ETSAB-UPC

\section{Organización}

Rodrigo Carbajal Ballell (humAP)

Dr. Arquitecto, Departamento de Proyectos Arquitectónicos, ETSA-US

Jordi Franquesa (Coordinador GILDA)

Dr. Arquitecto, Departamento de Urbanismo y Ordenación del Territorio, ETSAB-UPC

Joan Moreno Sanz (GILDA)

Dr. Arquitecto, Departamento de Urbanismo y Ordenación del Territorio, ETSAV-UPC

Silvana Rodrigues de Oliveira (humAP)

Arquitecta, Departamento de Proyectos Arquitectónicos, ETSA-US

Judit Taberna (GILDA)

Arquitecta, Departamento de Representación Arquitectónica, ETSAB-UPC

\section{Comité Científico JIDA'17}

\section{Rodrigo Almonacid Canseco}

Dr. Arq., Dpt. de Teoría de la Arquitectura y Proyectos Arquitectónicos, ETSA Valladolid

Fernando Álvarez Prozorovich

Departamento de Historia y Comunicación, ETSAB-UPC

\section{Atxu Amann Alcocer}

Dra. Arquitecta, Departamento de Proyectos Arquitectónicos, ETSAM-UPM

\section{Silvia Blanco}

Dra. Arquitecta, Centro Superior de Estudios de Galicia, Universidad San Jorge 


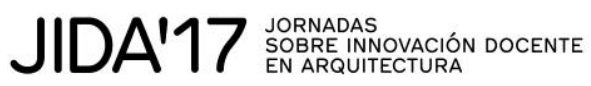

\section{Ivan Cabrera i Fausto}

Dr. Arq., Dpt. de Mecánica de los Medios Continuos y Teoría de Estructuras, ETSA-UPV

\section{Raúl Castellanos Gómez}

Dr. Arquitecto, Departamento de Proyectos Arquitectónicos, ETSA-UPV

\section{Nuria Castilla Cabanes}

Dra. Arquitecta, Departamento de Construcciones arquitectónicas, ETSA-UPV

\section{Eduardo Delgado Orusco}

Dr. Arquitecto, Departamento de Proyectos Arquitectónicos de la Universidad de Zaragoza

\section{Mariona Genís Vinyals}

Dra. Arquitecta, BAU Centro Universitario del Diseño de Barcelona

\section{María González}

Arquitecta, Departamento de Proyectos Arquitectónicos, ETSA-US

\section{Antonio Juárez Chicote}

Dr. Arquitecto, Departamento de Proyectos Arquitectónicos, ETSAM-UPM

\section{Juanjo López de la Cruz}

Arquitecto, Departamento de Proyectos Arquitectónicos, ETSA-US

\section{Nieves Mestre}

Dra. Arquitecta, Departamento de Proyectos Arquitectónicos, Universidad Europea

\section{Francisco Javier Montero}

Dr. Arquitecto, Departamento de Proyectos Arquitectónicos, ETSA-US

\section{Antonio Peña Cerdán}

Arquitecto, Departamento de Proyectos Arquitectónicos, ETSA-UPV

\section{Ana Portalés Mañanós}

Dra. Arquitecta, Departamento de Urbanismo, ETSA-UPV

\section{Amadeo Ramos Carranza}

Dr. Arquitecto, Departamento de Proyectos Arquitectónicos, ETSA-US

\section{Jaume Roset Calzada}

Dr. Físico, Departamento de Física Aplicada, ETSAB-UPC

José Vela Castillo

Dr. Arquitecto, IE School of Architecture and Design, IE University (Segovia, Spain) 


\title{
Fast-Arq Fast-Arq
}

\section{Gil Gimenez, Paloma; Martínez Rodríguez, José Manuel}

Dpt. de teoría de la Arquitectura y Proyectos Arquitectónicos E.T.S.Arquitectura Valladolid palomagilb@gmail.com; immartinez7@gmail.com

\begin{abstract}
Fas-Arq, is an experience for learning Architectural Design III and IV of the third course, which is linked to the creative fields of architecture. The dynamic is free and voluntary. Warns students two days earlier on the instruments necessary for the works which are carried out in a common classroom and interaction completed. Teachers respond to practical questions and don't care to check the authorship of the results. He is not qualified solutions, only are exposed which might be of greater interest in an informal space. During 2016-2017 have been 9 Fast-Arq. Students and teachers have responded mostly contributing their time and skills to action. They have also collaborated with full freedom to approach, sociologists and architects that critically reflect limits with the teaching profession from several outlooks.
\end{abstract}

Keywords: inspiration, reaction, training and opportunity

\section{Resumen}

Fas-Arq, es una experiencia para el aprendizaje de Proyectos Arquitectónicos II y IV del tercer curso de la Carrera, que se vincula al ámbito creativo de la arquitectura. La dinámica es voluntaria. Se avisa a los alumnos dos días antes sobre los instrumentos necesarios para la realización de los trabajos que se llevan a cabo en un aula común y con interacción completa. Los profesores responden dudas prácticas y no se preocupan de comprobar la autoría de los resultados. No se califica las soluciones, solamente se exponen las que pudieran ser de mayor interés en un ámbito informal. Durante el curso 2016-2017 se han realizado 9 FastArq. Los alumnos y los profesores han respondido mayoritariamente aportando su tiempo y sus capacidades a la acción. También han colaborado con plena libertad de planteamiento, sociólogos y arquitectos que reflexionan críticamente desde varios campos límites con la docencia y la profesión.

Palabras clave: inspiración, reacción, inicio, entrenamiento, oportunidad

Bloque temático: Metodologías activas MA 
Fast-Arq, es una experiencia para el aprendizaje de Proyectos Arquitectónicos III y IV del tercer curso de la Carrera, que se vincula al ámbito creativo de la arquitectura y ha sido experimentada durante el curso 2016-17 en la E.T.S.A. Valladolid. Como parte del equipo coordinado por nosotros, han compartido docencia Eusebio Alonso, Miguel Angel de la Iglesia, Jesús de los Ojos, Javier Blanco, Flavia Zelli, Leonardo Tamargo, Valeriano Sierra, Angel Iglesias, Jesús Alba y José Antonio Lozano.Fast-Arq parte del hecho provocador de la arquitectura como experimento, investigación y descubrimiento. Tres estados en los que puede asentarse el saber de cualquier materia.

Fast-Arq parte del hecho provocador de la arquitectura como experimento, investigación y descubrimiento. Tres estados en los que puede asentarse el saber de cualquier materia.

En arquitectura, las ideas se originan por deseos que se esbozan a partir de un conjunto de datos. Cuando el proyecto se pone en marcha, la exactitud, no importa tanto, pero parte imprescindible del proceso son acciones inspiradas por cualquier detalle, apenas intuidas, automáticas, fragmentarias, imperfectas.

Se trata, de un modo práctico, de entrenar en las destrezas de un oficio que se mueve en atmósferas profesionales cada vez más complejas.
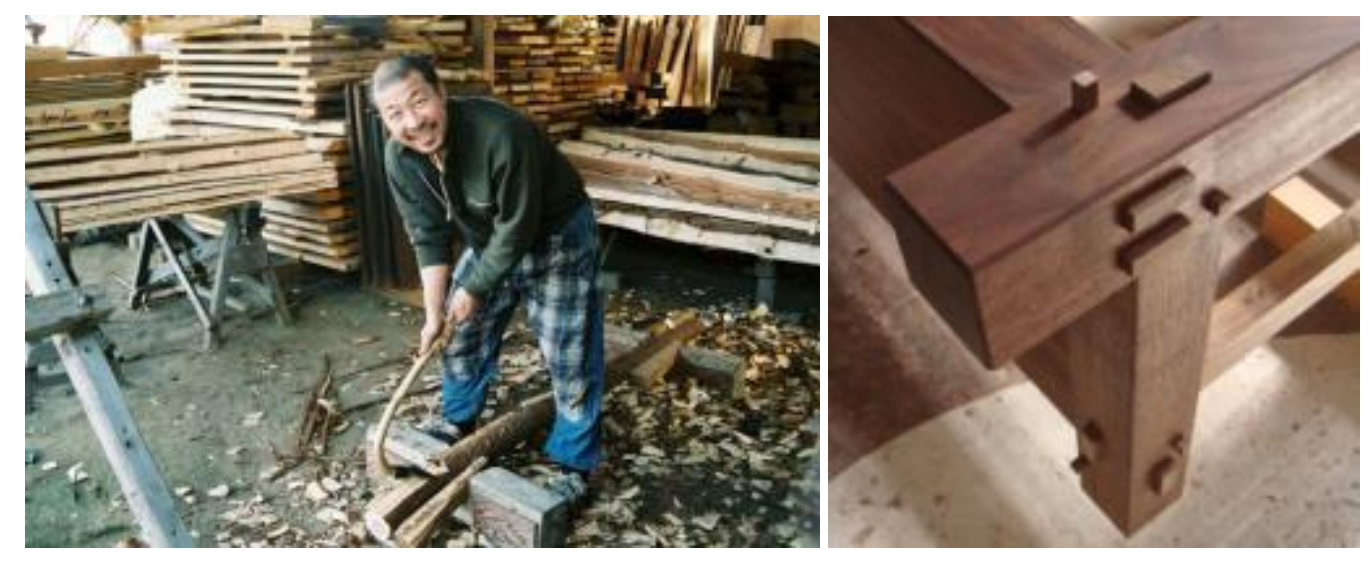

El entrenamiento lo entendemos como un recorrido largo en el que el paso por las aulas es apenas un instante. En el horizonte está la reflexión de Carlos Martí Aris cuando compara el modo de hacer de Arne Jacobsen con un atleta que corre de tal modo, tras tanto tiempo de práctica, que no se evidencia su esfuerzo. Dice Martí Aris: "Las obras de Jacobsen no quieren impresionar al espectador ni presentarse ante él como episodios singulares o emblemáticos. Suelen disponerse en el terreno con naturalidad, siguiendo formas geométricas elementales y prescindiendo de todo énfasis retórico. Parecen haber sido concebidas y construidas sin esfuerzo, con esa aparente facilidad a la que sólo puede llegarse tras un arduo y prolongado entrenamiento. Son obras en las que el trabajo ha sido capaz de borrar sus propias huellas. De ahí su levedad, su falta de dramatismo" (Martí, 2005). En la misma línea, con resignación y clarividencia ante acciones con menor protagonismo de autor, Santiago de Molina escribe:"' ¿qué tenía aquella obra que por muy fea y fracasada de fuera no permitía reírse de ella ni de su arquitecto?" esta pregunta, formulada por un amigo italiano de Jose Antonio Coderch cuando la visitaban, no deja de contener una dosis de optimismo y un tormento...la obra era fea, quizás insignificante, pero no risible. El único motivo que encontraba Coderch 
para esa falta de ridículo estaba en que el trabajo acumulado y el esfuerzo habían quedado arraigado misteriosa e inexplicablemente en las paredes de lo edificado." (De Molina, 2016)

Fast-Arq entrena y enseña a reaccionar velozmente ante las oportunidades. El ámbito de reflexión recrea, a los arquitectos como solucionadores de problemas, como pitonisos, que tantas veces han de sacar de la chistera la magia de la sabiduría, aunque los verdaderos misterios de la arquitectura, poco tienen que ver con la magia, ni con la suerte.

Pero por inmersión en la moda actual del movimiento y la vida informal sin asiento en caravanas y la oferta de determinados productos a través ellas, se seleccionan dos referencias gráficas con sentido lúdico y amable. La primera evoca la imagen Dr. King Schulz; dentista ambulante que existió en realidad, y es interpretado sarcásticamente como héroe maldito por Quentin Tarantino en su película "Django desencadenado". La segunda Puck cinema es (según refleja su publicidad) el cine más pequeño del mundo. Ha estado organizado por Toni Tomas y Carles Porta. Su propuesta ha sido proyectar de manera itinerante, dentro de una roulotte para grupos reducido de aficionados (http://www.puckcinema.com/).

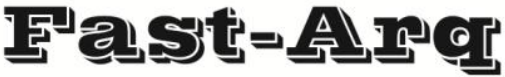

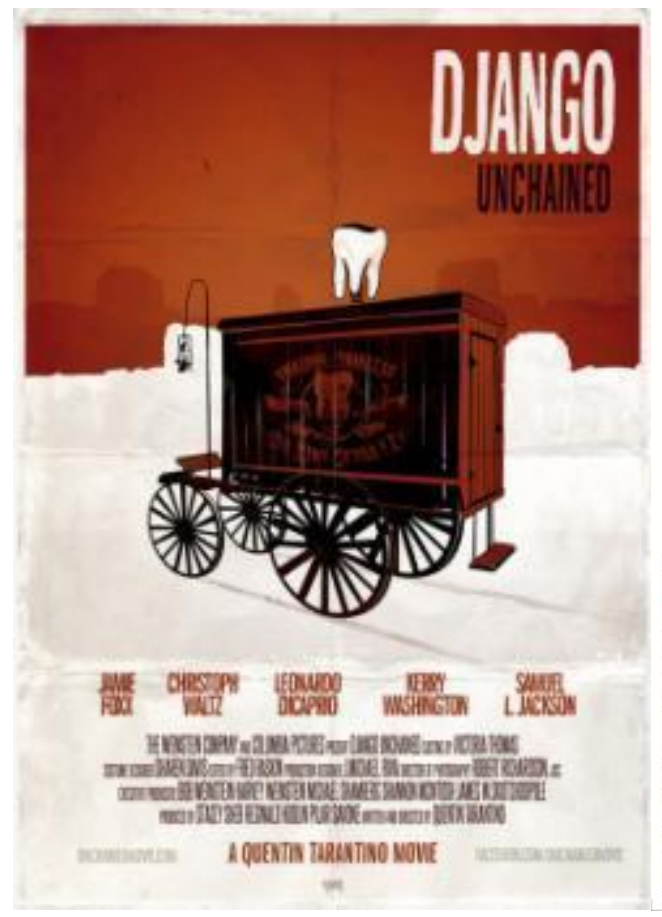

\section{Proyectos III / 2016-2017}

(pasillo del aulario)

|IIIII/| trabajos de reacción rápida ||IIIIIIIIIIIIIII| |IIIIIIIIII// inspiración a través de detalles /IIIII IIIII/ saber atender a las oportunidades IIIIIIIIII |||||||||||||||||||||| intuición ||||||||||||||||||||||||||||||||||||||| |IIIIIIIIIIII/ (trabajos de apoyo en el inicio) /IIIII
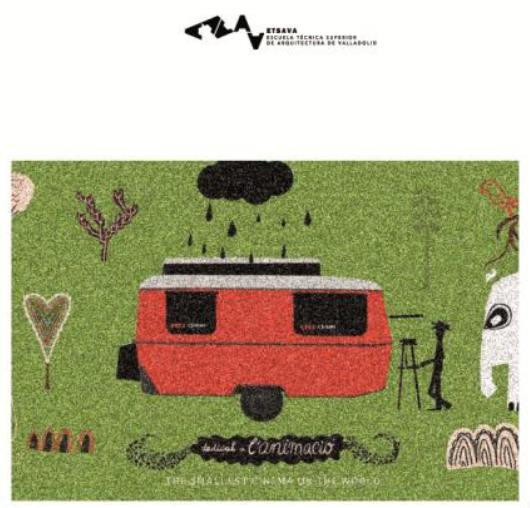

La idea ensoñadora de la conexión transversal entre conocimientos, disciplinas, oficios y experiencias se está revelando como deseo incumplido. Las interacciones son multifocales lanzamientos con posibilidad o no de acertar. En la medida en que el experto en la materia se halle en el sitio acertado, se encontrará con más posibilidades de acertar. En la medida en que se haya adiestrado en unas determinadas habilidades técnicas básicas, será más difícil, no salir, al menos airoso de los trabajos. En la medida en que adquiera experiencia con herramientas que propiamente, por naturaleza, es capaz de dominar, la magia que se solicita al prestidigitador, será en verdad, arquitectura, arte, resultado hermoso de motivos necesarios. EI doctor Schulz, continúa el itinerario sin rumbo en su carromato destartalado, acumulador y acogedor de sus herramientas. 


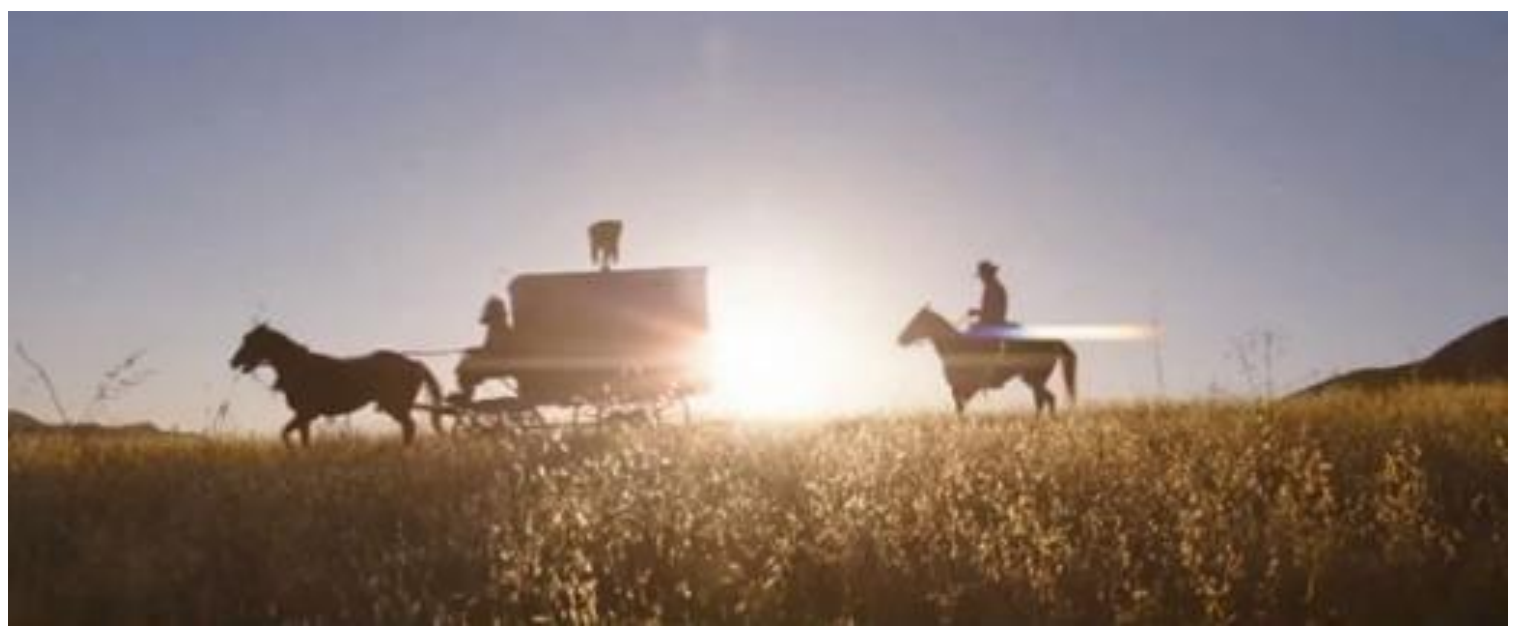

Puck Cinema no trata de solucionar problemas con la analogía de la medicina. La consulta no interesa, ni las recetas. Los viajantes atraen a su ámbito pequeño de oscuridad, con cachivaches seductores montados en torno (http://habitar.upc.edu/2015/07/02/puck-cinemaproyectando-dentro-roulotte/). A través de la exposición itinerante, de la comunicación programada de antemano, las personas curiosas se acercan a una posible interacción o los que pasan por allá cerca de donde se aparca la caravana. El motivo romántico de todo intento pervive, de un modo sencillo, en el paisaje de la cultura (Marías, 2005). ${ }^{1}$

Las dos referencias citadas conectan con modos escenográficos y muy actuales de presentarse las soluciones arquitectónicas ante la sociedad. Pero también conectan específicamente con la fase proyectual de inicio, de creatividad, imperfección e intuición en la que se cuentan apenas las ideas (de modo coloquial, se venden). Es la fase en la que se realizan dibujos imaginativos sin escala; que no son lentos ni precisos; son parciales; no son concretos; no descienden al detalle, o si; no interesa en ellos el avance y el retroceso y la coherencia es relativa; Paradójicamente pueden apuntar o no, medios o modos necesarios para que la arquitectura sea real, vislumbran soluciones sin materialización de instrucciones y ciertamente lo importante del proyecto está. Cabe mencionar aquí los apuntes de Alejandro de Sota, Ruhe Nishisawa, Oscar Niemeyer, Eliel Rasmussen o Paulo Mendes da Rocha, todos bien conocidos como lanzamientos al aire de las ideas, premonitorios como "magia" de las soluciones finales porque la intimidad de la belleza ya está el ellos (Lipovetsky, 2016).

El recorrido itinerante o la deriva son parte de todo proceso creativo. En todo aspecto objetivo de un proyecto hay una circunstancia común que es su propia dualidad incompatible con un análisis, ordenación, clasificación y valoración estrictamente científicos. Esto ocurre a causa de la interferencia del deseo, de la subjetividad, de la experiencia, de la imaginación, y del entendimiento individuales; del azar. En la realización de un descubrimiento científico existen unos datos probados que se complementan con otros buscados hasta llegar a un final, que puede ser insólito, pero se prevé o se busca. En el descubrimiento arquitectónico, cada final debería ser insospechado, porque cada vez, los datos son inesperados. Llevados al extremo, el deambular incierto, el recorrido involuntario, fueron elementos estructurantes de los fundamentos surrealistas. Más recientemente marcaron una etapa en la obra y en la actividad docente de Rem Koolhaas. En 1975, Koolhaas comenzó a impartir clases en la Architectural

\footnotetext{
1 "Solíamos llegar con la película ya empezada, lo cual suponía un ejercicio de imaginación y deducción fabuloso (qué había sucedido antes para que los personajes estuvieran en lo que estaban) y un pretexto magnífico para quedarse luego a ver de nuevo la cinta entera."
} 
Association Diploma Unit 9. Allí puso en marcha un sistema metodológico en el que se fomentó el interés por el inconsciente y la utilización de sistemas no racionales en la producción del proyecto arquitectónico. El automatismo seria la vía de trabajo. En algunas propuestas provocaba un bucle aparentemente inverso al que generan las soluciones formales habituales alterando los parámetros de la información y Los datos que normalmente se suceden, se transgredían. Su intento docente radicó en la abstracción y la discusión del concepto de forma. Fomentó la creatividad en la niebla del inconsciente y buscó anular los procesos racionales de proyecto. Promovió, por ejemplo, desarrollar un proyecto sin programa ni ubicación partiendo de una forma fija. Sobre la forma se bombardeaban los programas imaginados y a continuación se iniciaba la fase de localización de la pieza (Arias, 2016). En S,M,L,XL define deriva como: "un modo de comportamiento experimental ligado a las condiciones de la sociedad urbana: una técnica de pasajes transformados a través de ambientes que varian" (OMA, 1995). En el sistema de Koolhaas entra en juego un posicionamiento radical, en cierto sentido fundamentalista sobre el proceso de creación. Nada que ver con las dinámicas actuales de debate acerca de lo inmaterial (Lipovetsky, 2016, p.218). ${ }^{2}$ Recientemente en la Bartlett School of Architecture de Londres se ha celebrado un simposium, no sobre la innovación docente, sino sobre la pertinencia de romper los cánones en la enseñanza. Ante la certeza de la información rápida y casual, el valor de la especulación, la crítica y la constitución de competencias curriculares, éste es un dilema inédito, que probablemente se resolverá en medio de la incertidumbre con la que se han resuelto los cambios y dando por hecho que las transformaciones profundas en su velocidad propias, no suelen ser esencialmente divertidas.

La dinámica de Fast-Arq es voluntaria. Se avisa a los alumnos dos días antes sobre los instrumentos necesarios para la realización de los trabajos que se llevan a cabo en un aula común y con interacción completa. Durante el curso 2016-2017 se han realizado 9 Fast-Arq. Han sido pequeños ejercicios de dos horas máximo, enmarcados en el ámbito de los proyectos reflexionados y elaborados a lo largo de varias semanas. Así se solapan dos velocidades, dos tiempos; el tiempo de la rapidez y el de la lentitud, ambos como contraste y como complemento. Los profesores responden dudas prácticas y no se preocupan de comprobar la autoría de los resultados. No se califica las soluciones, solamente se exponen las que pudieran ser de mayor interés en el ámbito informal de un hall intermedio de la Escuela que sirve de paso a los talleres de otras asignaturas.

Los alumnos y los profesores han respondido mayoritariamente aportando su tiempo y sus capacidades a la acción. También han colaborado con plena libertad de planteamiento, sociólogos y arquitectos que reflexionan críticamente desde varios campos límites con la docencia y la profesión.

En uno de los ejercicios largos se propone insertar un programa de uso en un esqueleto urbano abandonado. Sobre la posibilidad de habitar los esqueletos urbanos existen procesos en curso que tratan de recopilar datos; también trabajos teóricos, algunos de los cuales que se han llevado a la práctica o han servido como plataforma de diversas experiencias con voluntad transversal en los últimos años. Pero desde un punto de vista de su potencial instrumental, interesa resaltar su neutralidad como objetos abstractos, su lectura como elementos o modelos a partir de los cuales es posible operar con libertad. Con la perspectiva de todo lo acontecido en la modernidad, muchas estructuras desnudas y abandonadas remiten al modelo Domino, inventado por Le Corbusier como prototipo edificatorio para tiempos y causas de emergencia.

\footnotetext{
2 "Para mi, la levedad se asocia con la precisión y la determinación, no con la vaguedad ni con el abandonarse al azar. Paul Valery dijo: Hay que ser ligero como el pájaro, no como la pluma".
} 
El título del primer Fast-Arq correspondiente a la reflexión sobre el esqueleto urbano abandonado es "Habitar una serpiente". Su objetivo es centrar las posibilidades abstractas de las formas para entender la flexibilidad que les ayude a sobrevivir. Esto pasa por discutir su contenido, los apriorismos, las apariencias. La supuesta rigidez de una estructura reticulada a partir de la cual se organiza el proyecto.

Afirmar que las apariencias engañan es promocionar discusiones sobre la estabilidad de los límites y las referenciás estáticas. Para desencadenar este proceso se toma como referencia el texto y los dibujos de El Principito de Antoine de Saint-Exupéry. En el relato, los observadores confunden la intención del muchacho que está expresando una realidad tal y como él la ha conocido. ${ }^{3}$ Se propone, pues, la posibilidad de habitar una serpiente de 3 metros diámetro mínimo en su interior, hasta aumentar lo que cada idea de ocupación (sin masticar, como las serpientes)requiere.

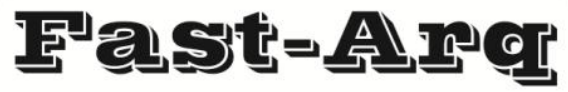 I}

\section{Habitar una serpiente}

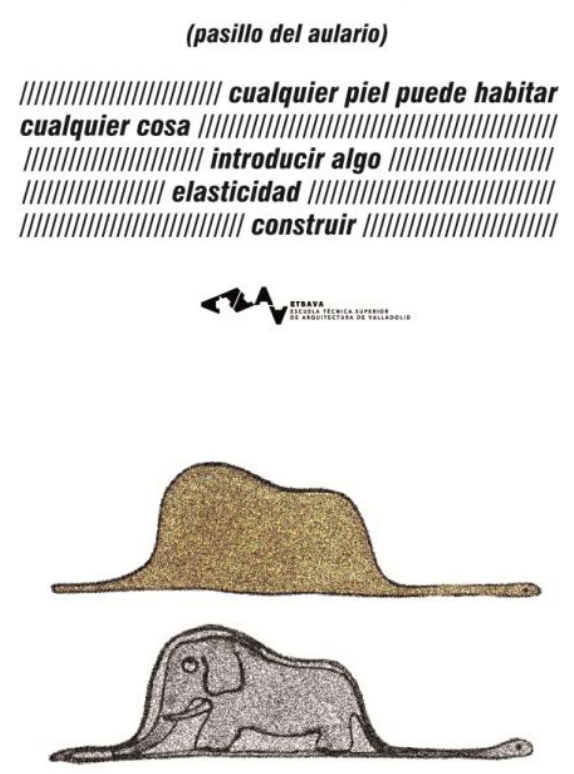

Ejemplo 1

\footnotetext{
3 "Cuando yo tenía seis años vi una vez una lámina magnífica en un libro sobre el Bosque Virgen que se llamaba Historias Vividas. Representaba una serpiente boa que se tragaba una fiera...El libro decía: "las serpientes boas tragan a sus presas enteras, sin masticarlas. Luego no pueden moverse y duermen durante seis meses la digestión" Reflexioné entonces sobre las aventuras de la selva y a mi vez, logré trazar con una lápiz de color mi primer dibujo...Mi dibujo no representaba un sombrero. Representaba una serpiente boa que digería un elefante. Dibujé entonces el interior de la serpiente boa a fin de que las personas grandes pudiesen comprender".
} 


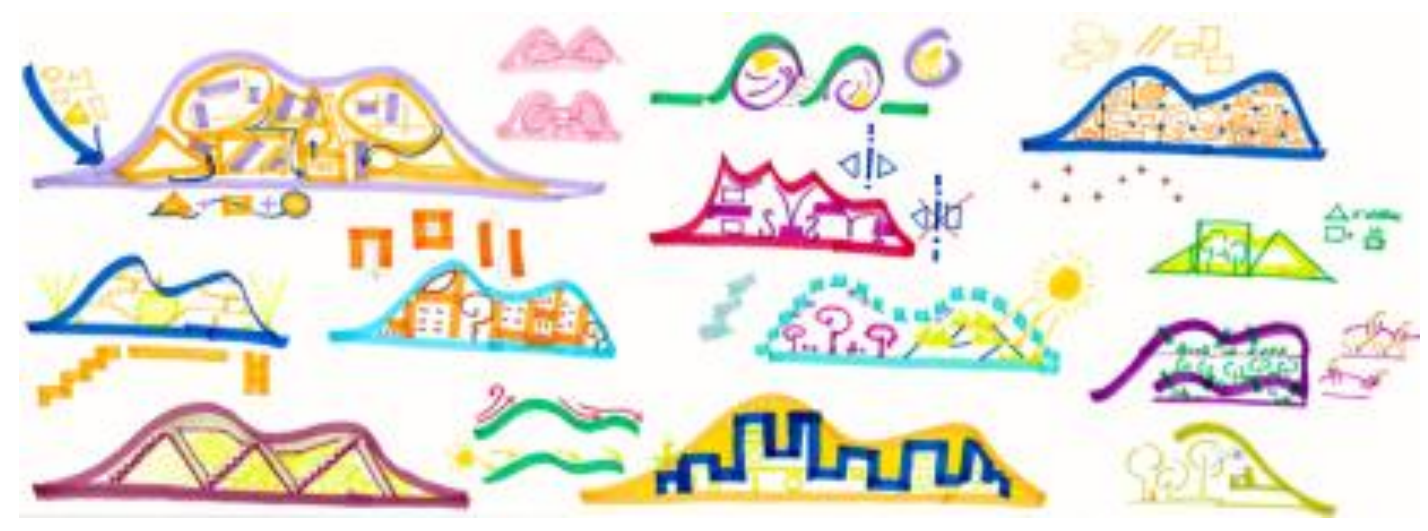

Ejemplo 2

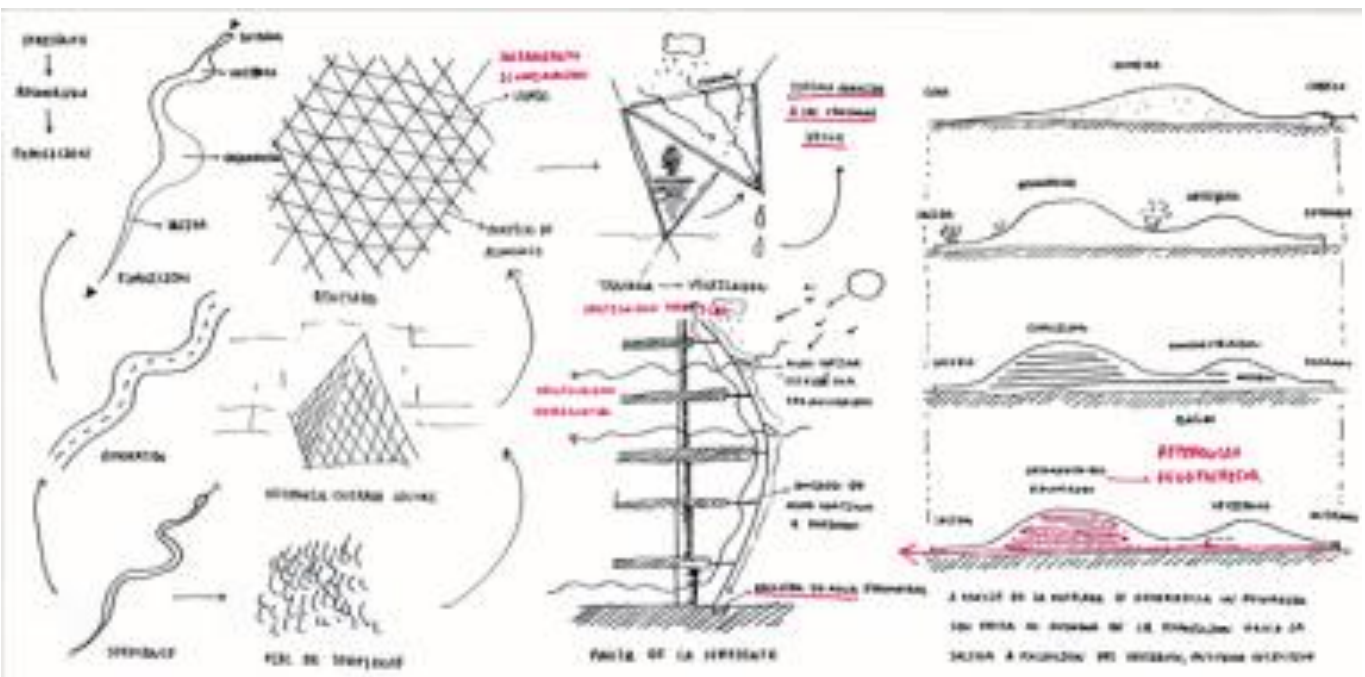

Ejemplo 3 


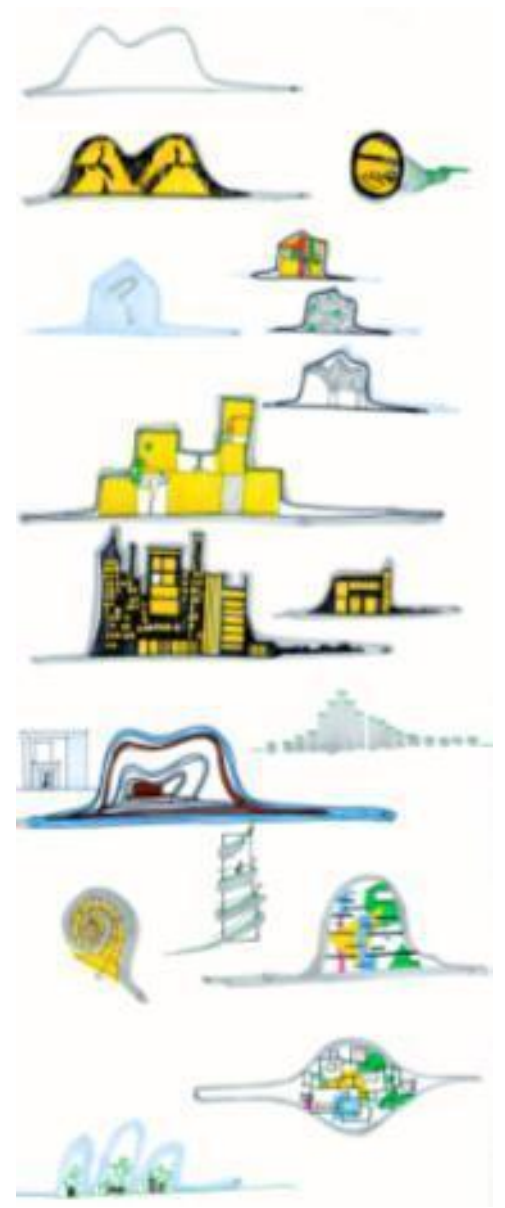

Ejemplo 4

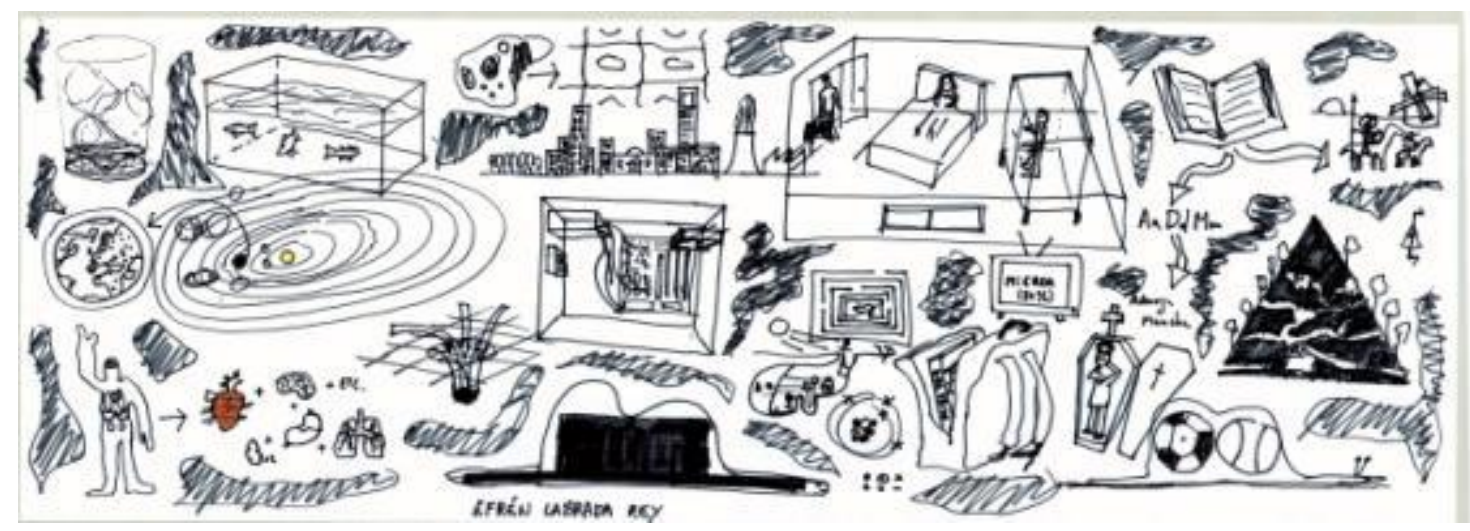

Fast-Arq 2 se oferta para entender mejor al púbico hacia el que trabajamos los arquitectos, su entorno, su visión y sus necesidades. El primer paso es identificar los personajes que pueden habitar los espacios. El segundo paso consiste en humanizarlos (con un nombre decidido para él y la historia de sus días), empatizar (con un concepto que lo evoca, una única palabra guia para la construcción de la forma). Finalmente se valida el proceso argumentando verbalmente y con una maqueta que construye la atmósfera buscada. La maqueta es construida mediante materiales simples: cartón y pajitas, como posibilidad concreta de maniobrar con líneas y planos. 

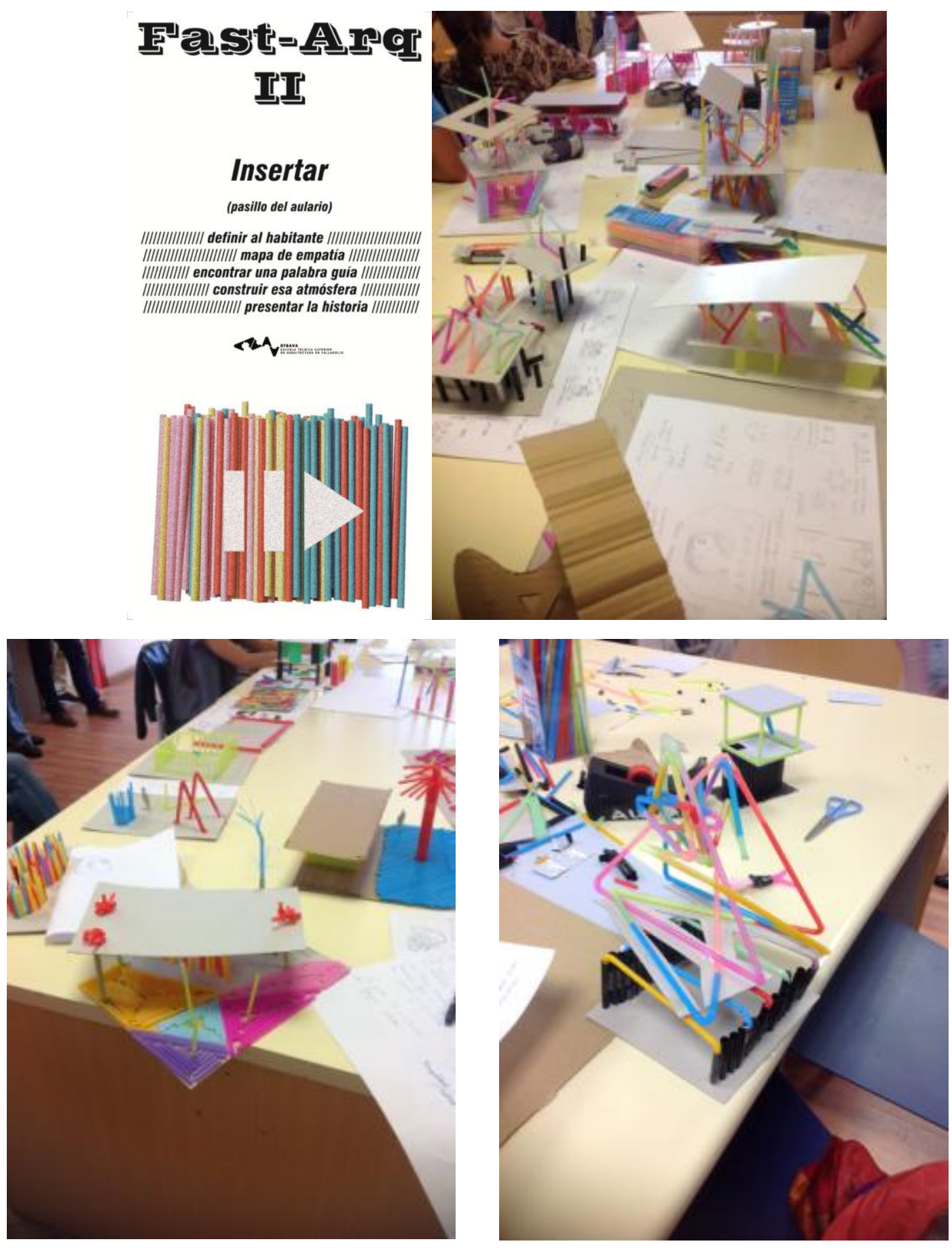


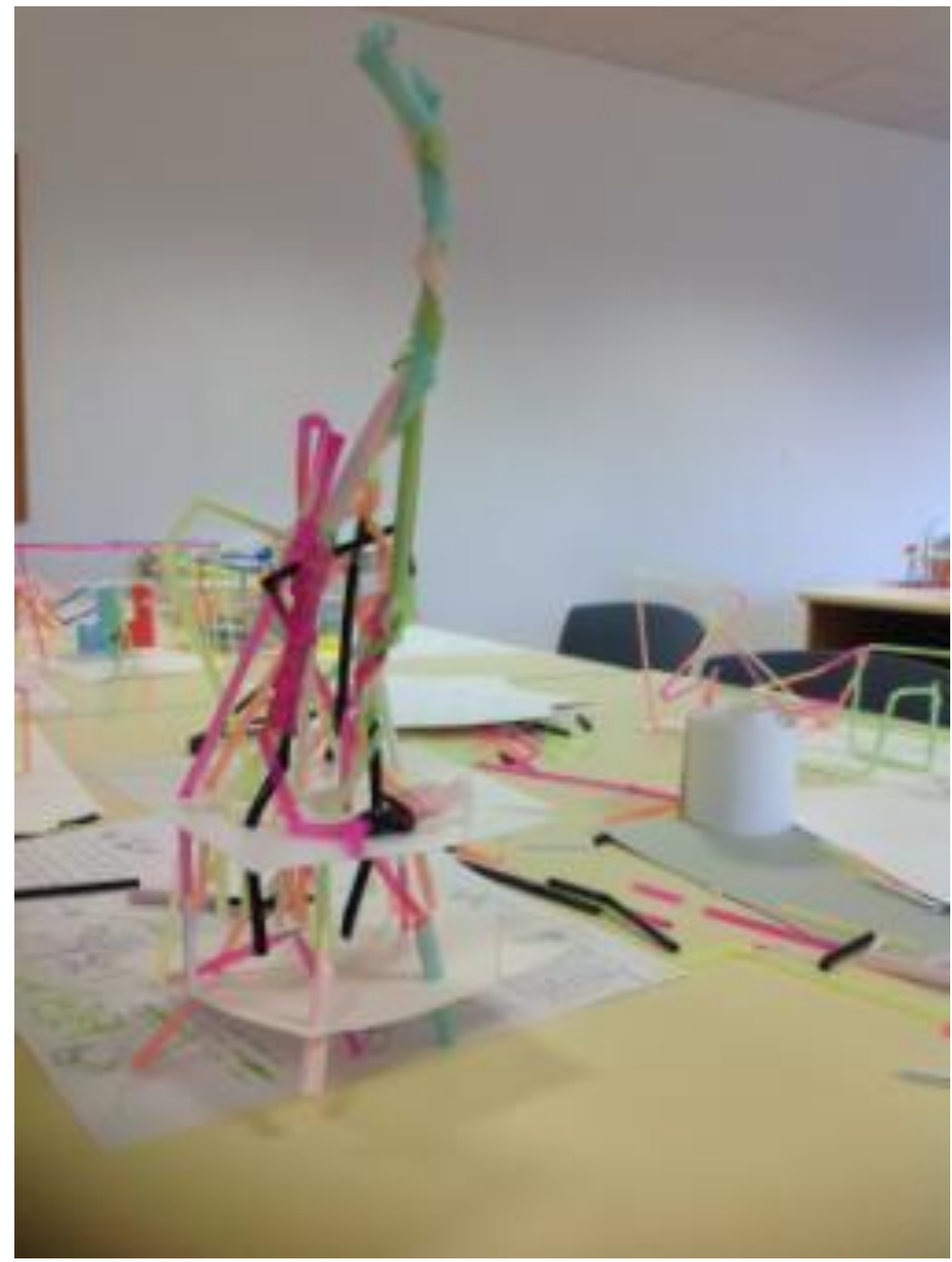

Fast-Arq 3 introduce un ejercicio de cinco semanas que consiste añadir un programa a un edificio existente como la suma o unión de una cosa a otra, de manera que se forma un todo homogéneo. Es el proyecto de un aumento en algún sentido, perteneciendo a la misma cosa. La relación posición-forma propone una relación entre el orden de lo que existe y orden de lo que se añade. La idea de preexistencia conduce a meditar sobre lo interior y lo exterior como respuesta al lugar. La solución es estructural en forma y espacio. El esqueleto es lógico y material. El proyecto investiga una metodología cuyo objetivo es la recuperación de un edificio desalojado y en venta, en una avenida, frente a un parque, para la reactivación de su vida. 


\title{
Fist $=A$ N \\ IIT
}

\section{Espacio A-4}

\author{
(oasillo del aulario)
}

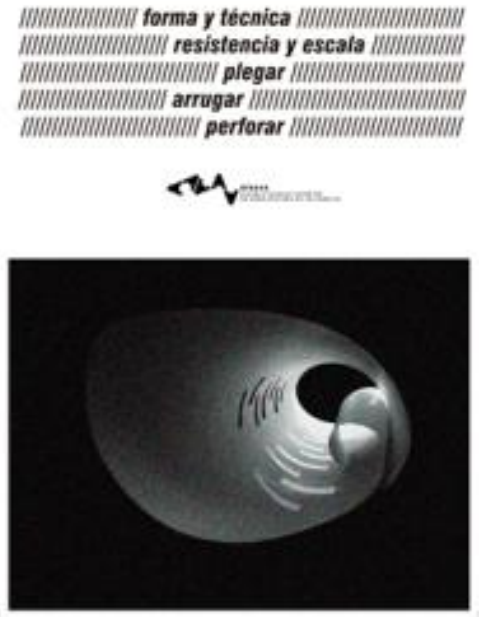

Después de la explicación detallada del ejercicio, se pone en marcha Fast-Arq 3 con la descripción literaria de esta situación:

"Pablo, Reiner y Maria son tres estudiantes de arquitectura. Como el verano se prolonga, han quedado el 11 de Octubre en la terraza de un bar de Valladolid. Están hablando de estructura y espacio.

- La forma tendría que ser consecuencia lógica de la técnica.

- Yo aún no sé nada de estructuras ni de construcción...

- El ojo es un instrumento matemático seguro, establece enseguida la escala que el cálculo puede desarrollar a su debido tiempo.

- Hablando de esto, he encontrado un libro sobre las grandes estructuras de Detroit, Michigan y Cininnati. Explica que inicialmente no son problema de cálculo: “... el espacio abarcante o único está liberado de la lógica de las partes. Es resistente a la escala. Se refiere a un todo homogéneo. Es un organismo sin centro. Es único, no sólo porque se desarrolla en un solo nivel, sino porque se gobierna con una sola decisión".

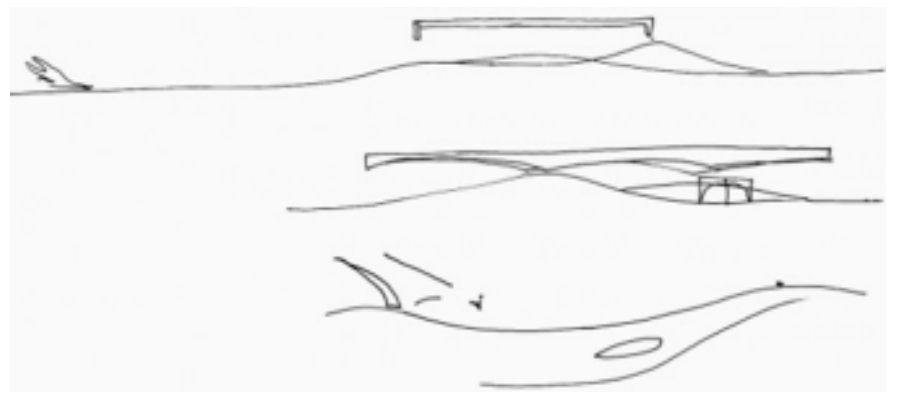

Paulo Mendes da Rocha. Pabellón de Brasil para la Expo. Osaka 
En una hora, únicamente con un folio en blanco, los alumnos crearon una propuesta de espacio único mediando la superficie y la luz en contraste (Cortés, 2003). ${ }^{4}$ La acción se realiza doblando, haciendo cortes, arrugando, perforando, plegando, fisurando, etc. y terminó con fotografías realizadas con el teléfono móvil que enviaron cada uno a su profesor.
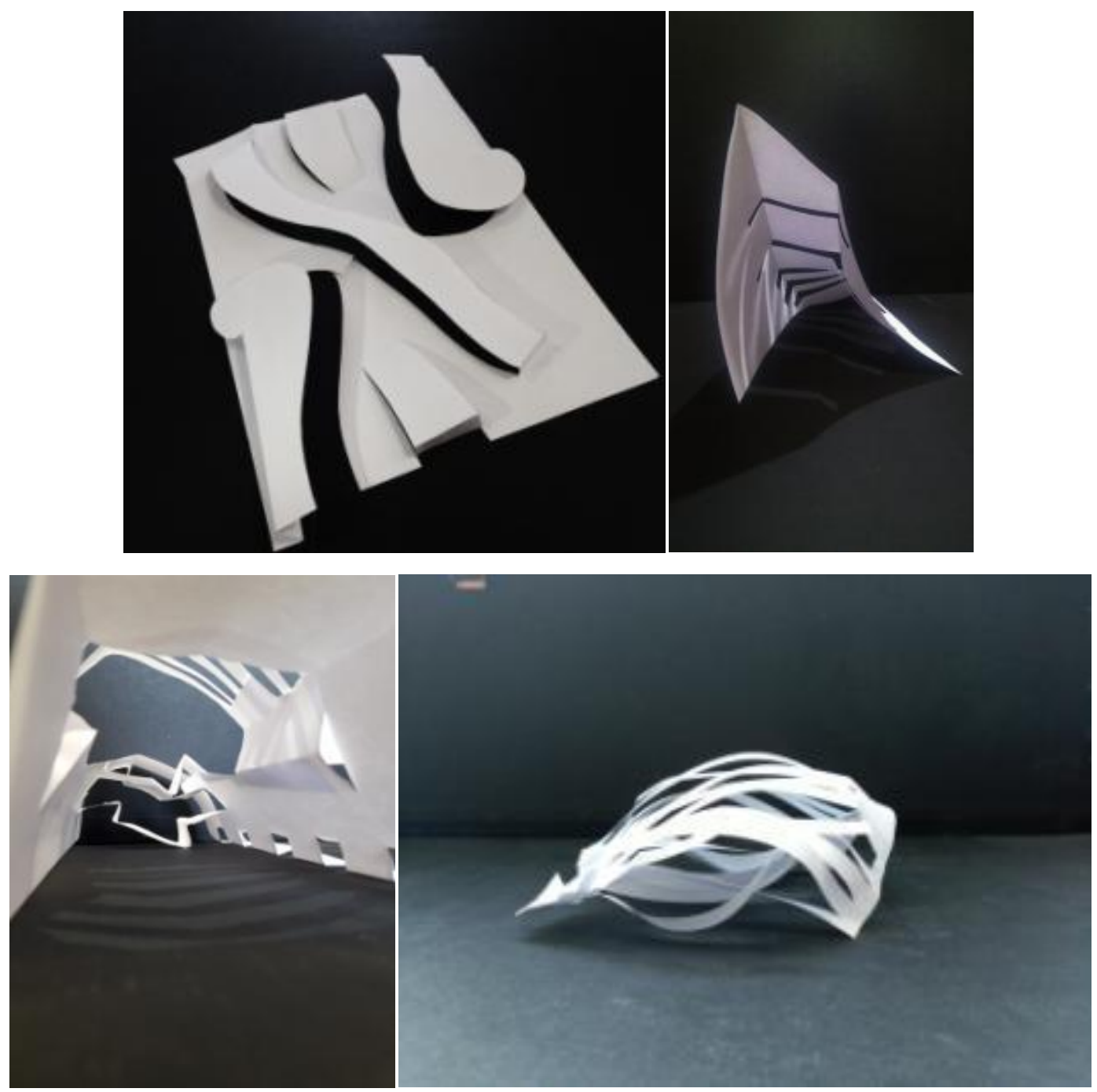

\footnotetext{
4 "La arquitectura percibida en forma sencilla e inmediata es una combinación -revelada por medio de luces y sombrasde espacios masas y líneas" Cit en BANHAM, Reiner ; Teoria y diseño en la primera era de la máquina. Barcelona 1985, Paidós, p.68 Cfr. Ibid. pp.34, 180,"..aqui la losa del piso se dobla verticalmente hacia arriba en el extremo de los voladizos y se convierte en pared exterior. Ibid. P.273. "El edificio adquiere una nueva consistencia en su envolvente, cuya supuesta masividad es, sin embargo, negada por la actividad y la experiencia de movimiento que se desarrolla dentro de la misma y por la condición ligera y visualmente cambiante del propio cerramiento".
} 


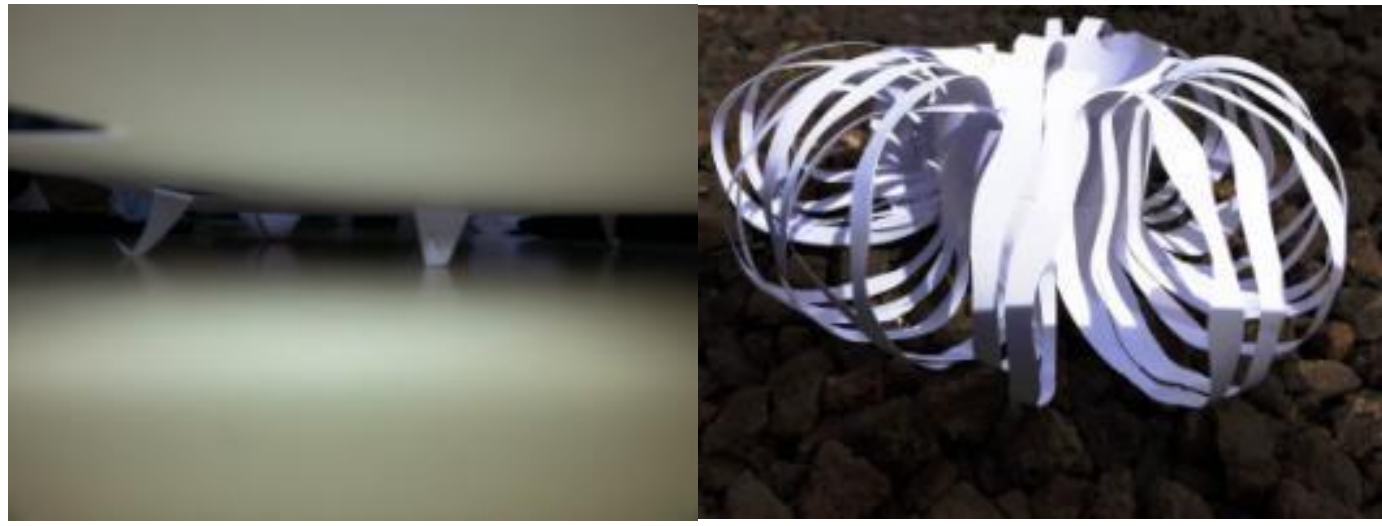

El último Fas-Arq del curso se centra en el concepto de "colocar". Introduce el procedimiento de coser algo nuevo al lado de algo existente, a continuación; emplazar; relacionar sistemas. Algo elemental en todo proyecto nuevo de arquitectura dentro de un contexto.

El inicio de la acción comienza con el repato aleatorio a los alumnos, según llegan al espacio de trabajo, de tres packs con 3 folios grapados. En cada uno está representado un ámbito urbano diferente.

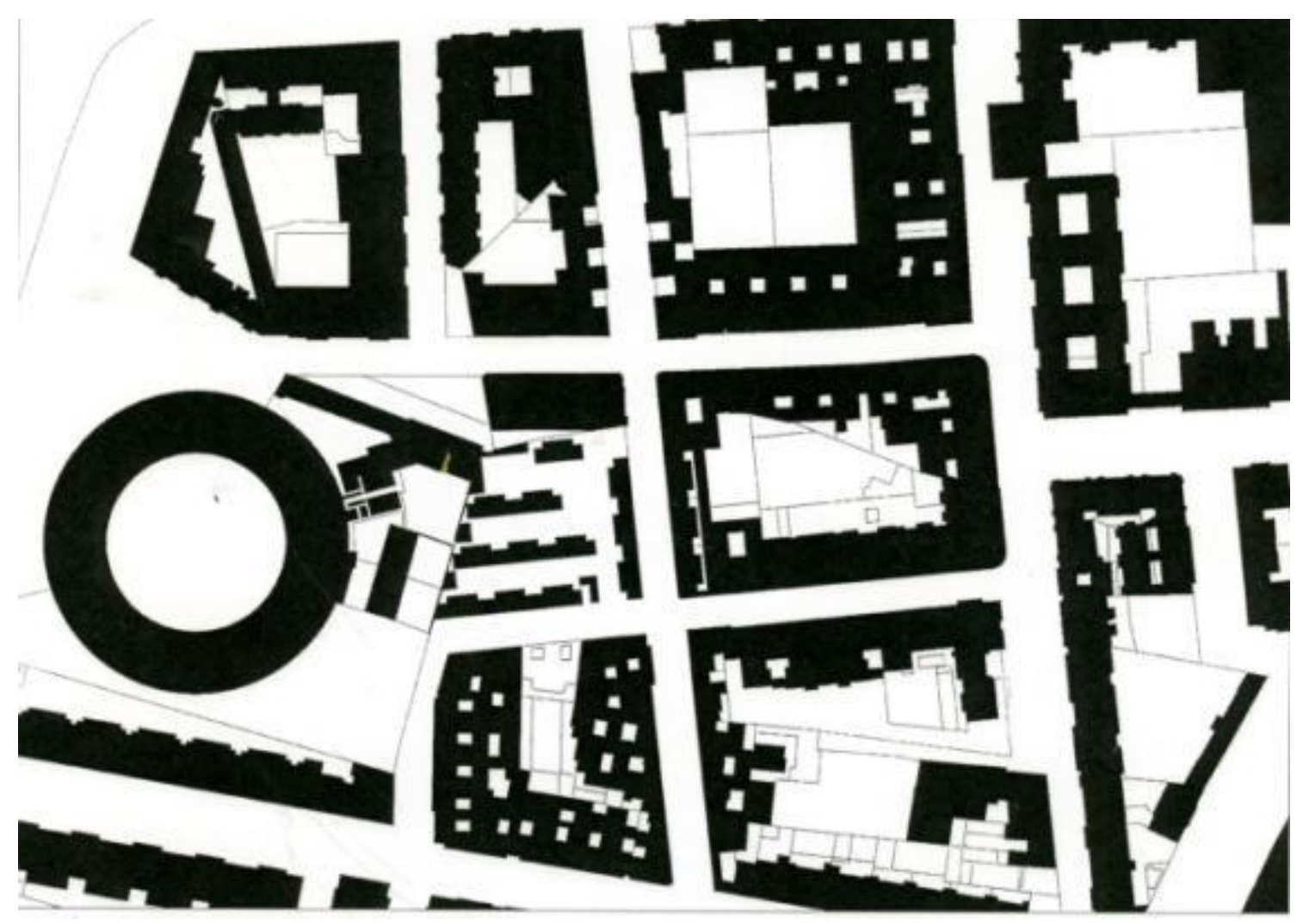

Contexto 1. Entorno de la plaza de toros de Valladolid 


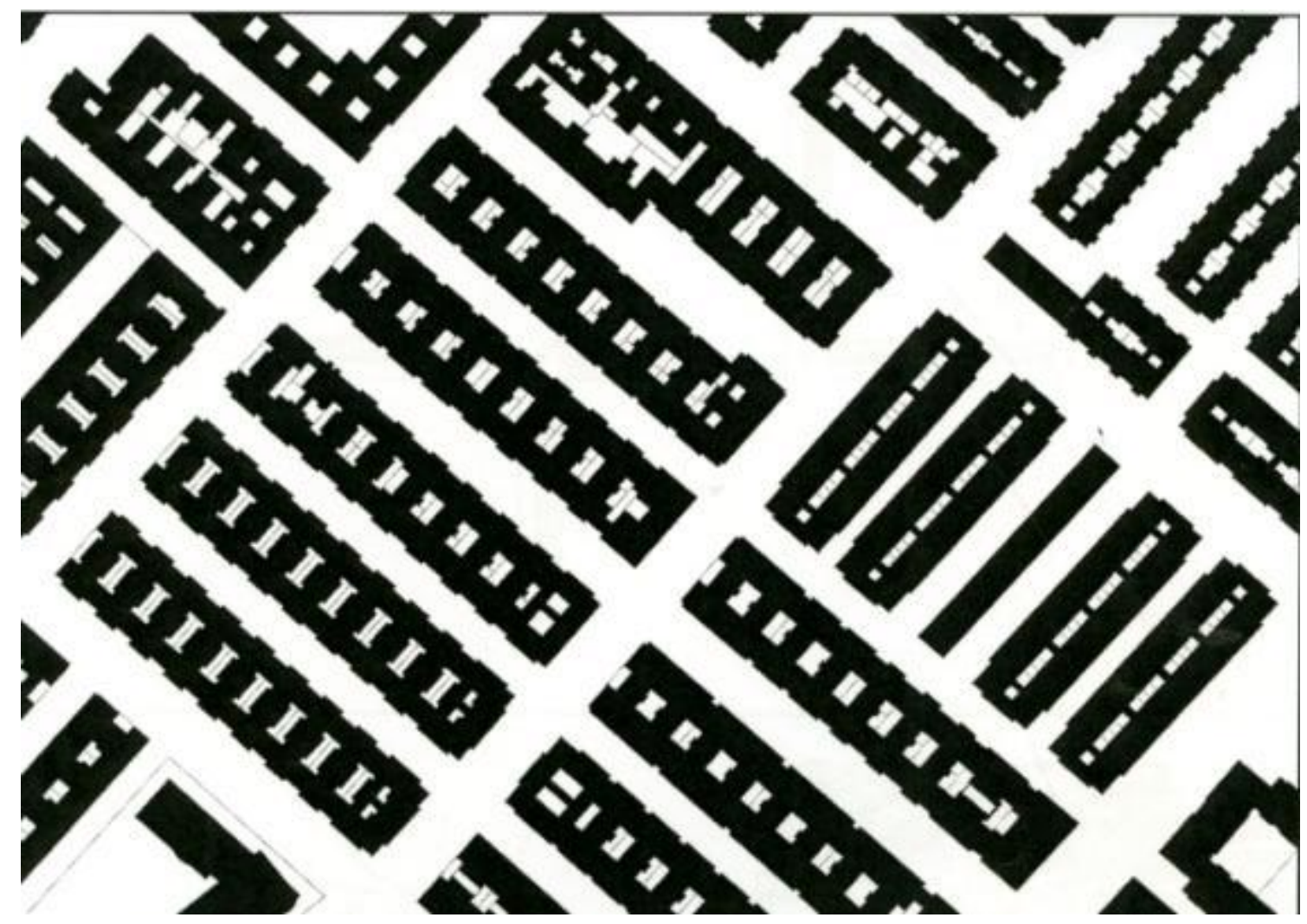

Contexto 2. Barrio de la Rondilla. Valladolid

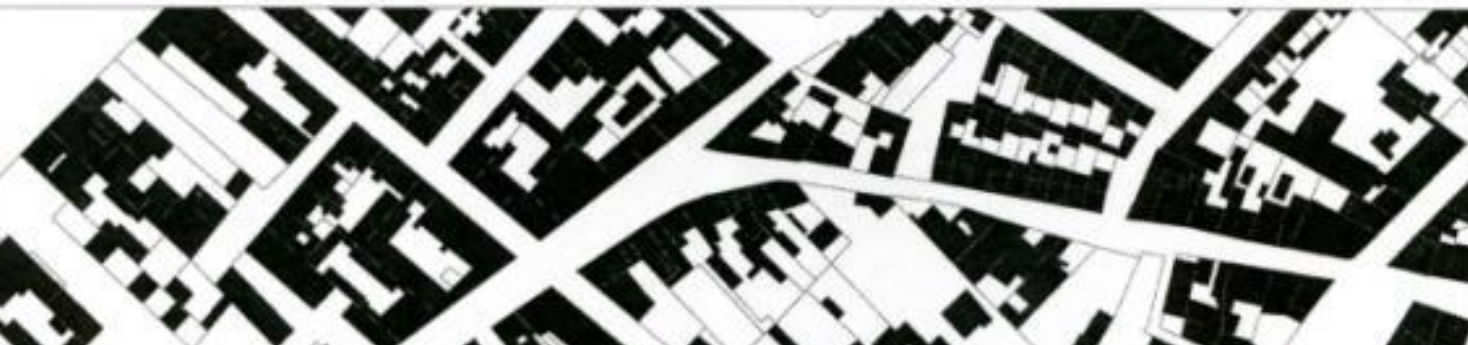

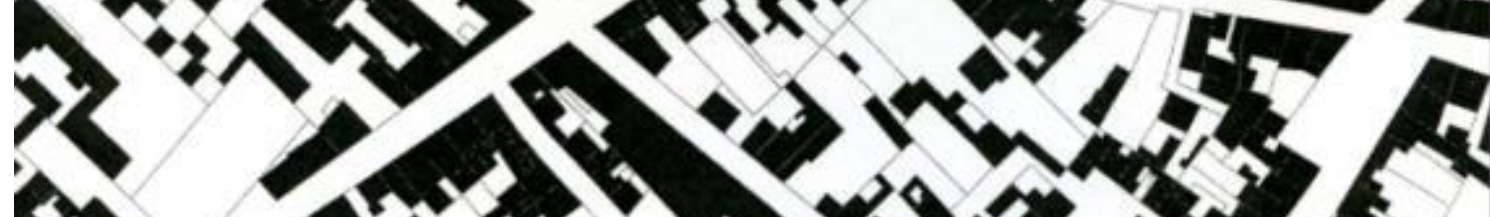

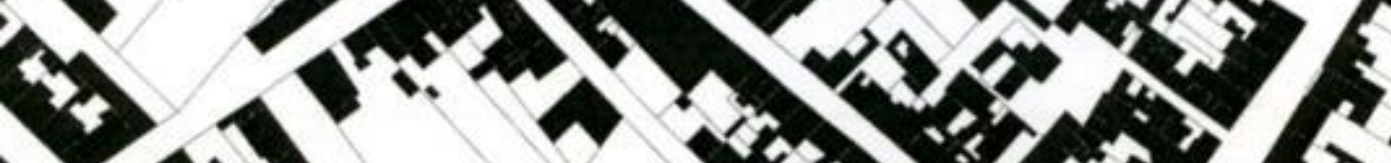

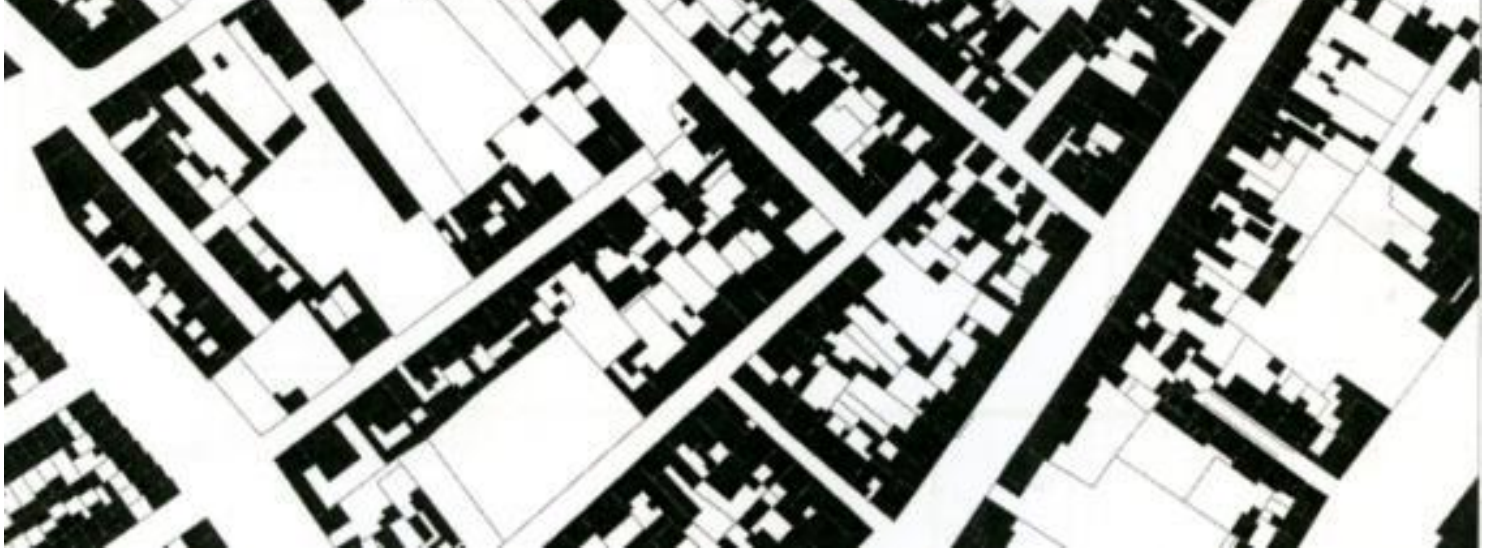

Contexto 3. Barrio España. Valladolid 
En los tres ábitos se supone un vaciado urbano, que se les entrega como plantilla. Se provoca un trabajo de ocupación posible a partir de tres modelos formales. Al contexto 1 le corresponde la referencia al edificio de apartamentos en Okurayama (SANAA 2008). Los alumnos que les ha correspondido el contexto 2, trabajan con el proyecto de Alison y Peter Smithson para Golden Lane (1952). Para el contexto 3, un barrio de pequeñas casas molineras, interpretan manipulan y proyectan mediante la estructura formal de las casas patio de Mies van der Rohe (1931-38)

Se trata de operar con libertad casi naif, ante la trama urbana como soporte sobre el que se realiza la actuación. Pero el objetivo sería provocar un análisis crítico, para entender las ciudades como organismos vivos, como escenarios de cambios y desarrollos colectivos, algunos visibles y otros más invisibles. Ayudar a entenderlas como acumulación de sistemas, elementos o episodios condicionados: planes urbanísticos, edificios, paisajes, topografía, recorridos, ambiente, población, escala, usos, orientación, etc.
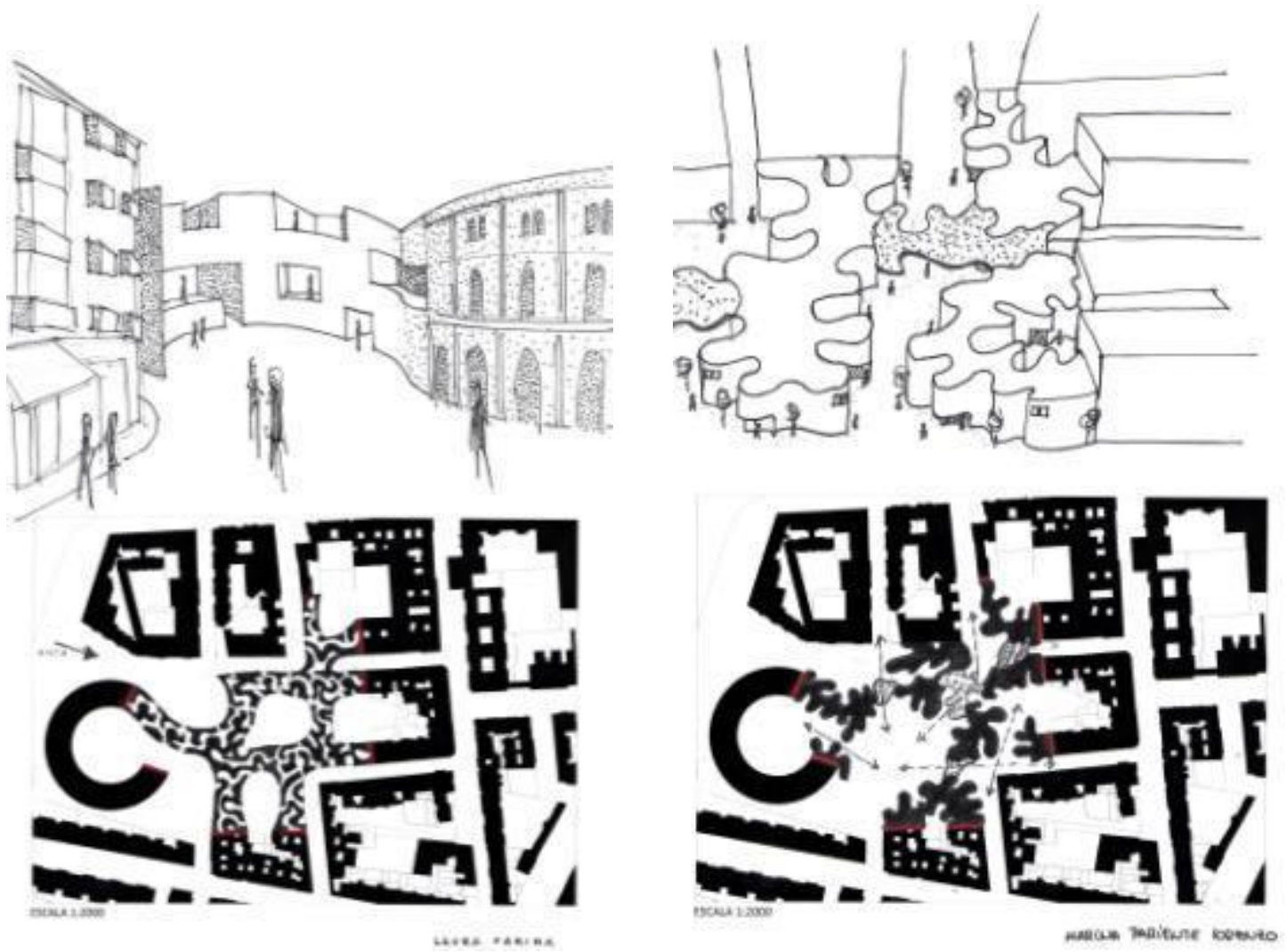

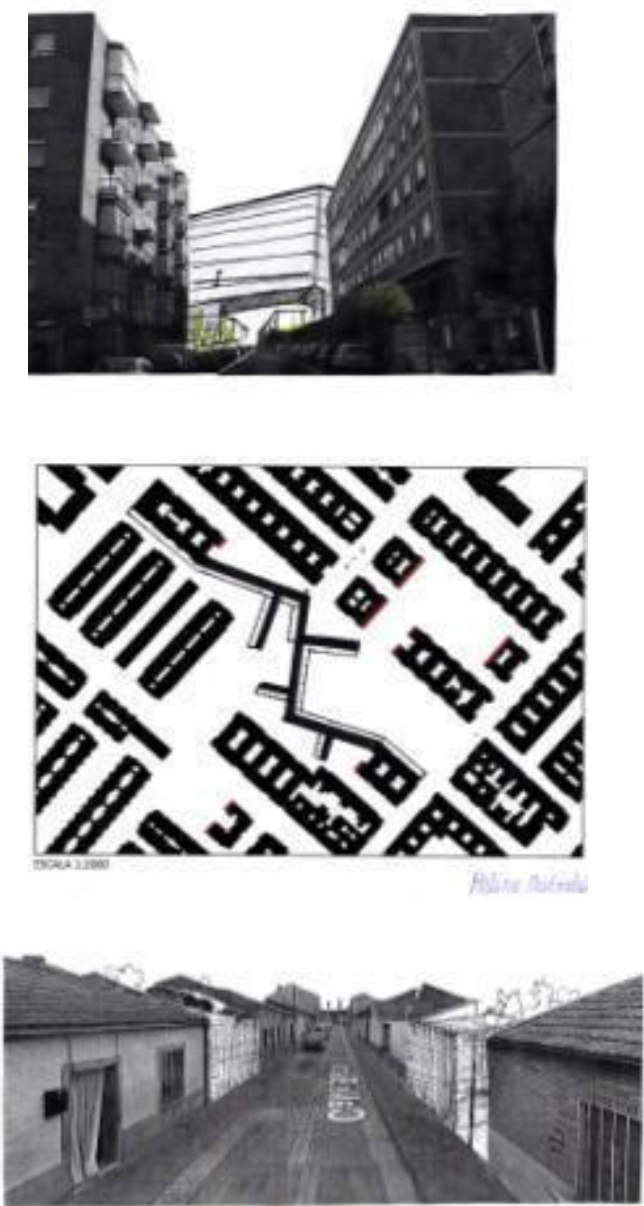
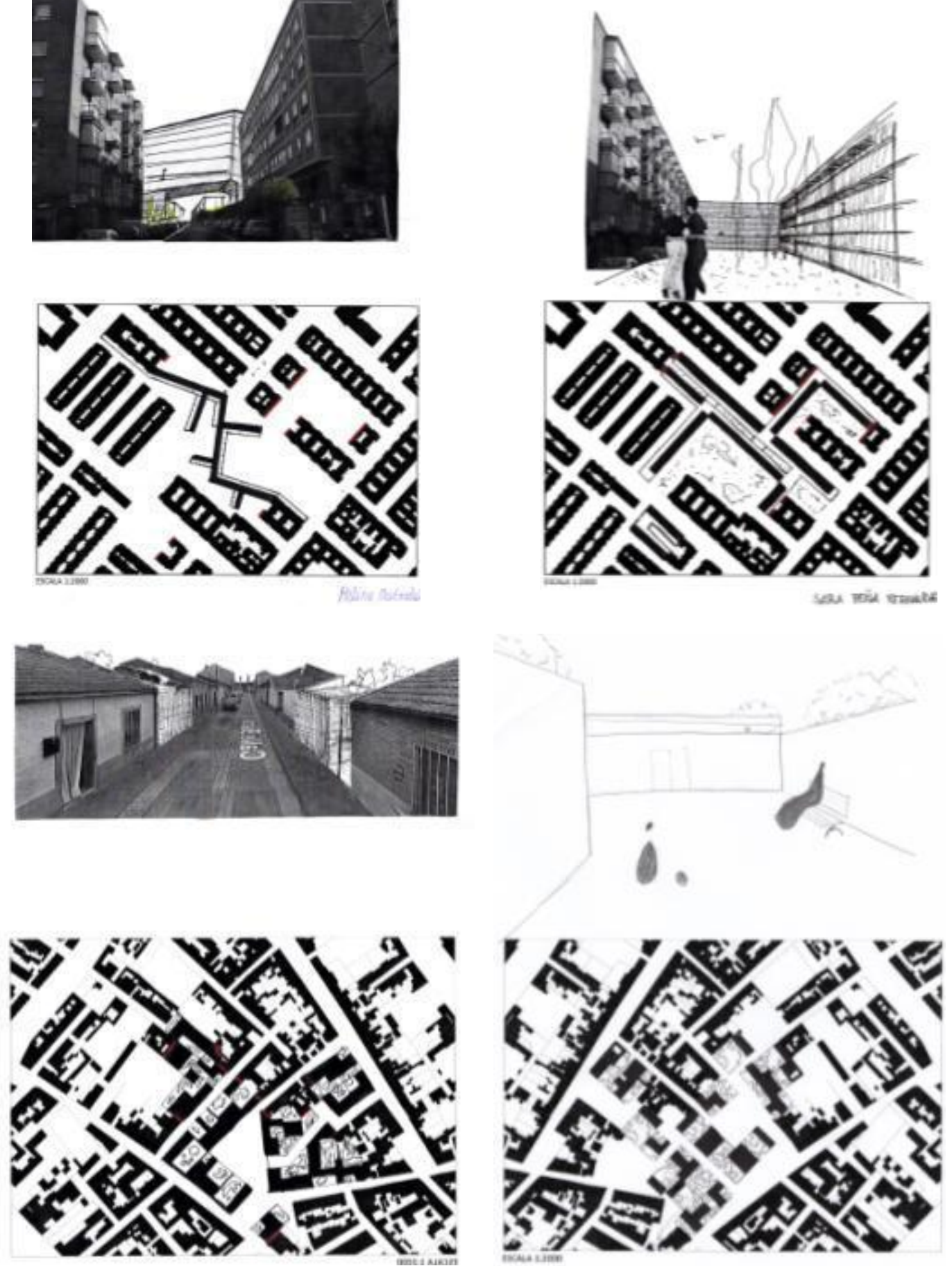


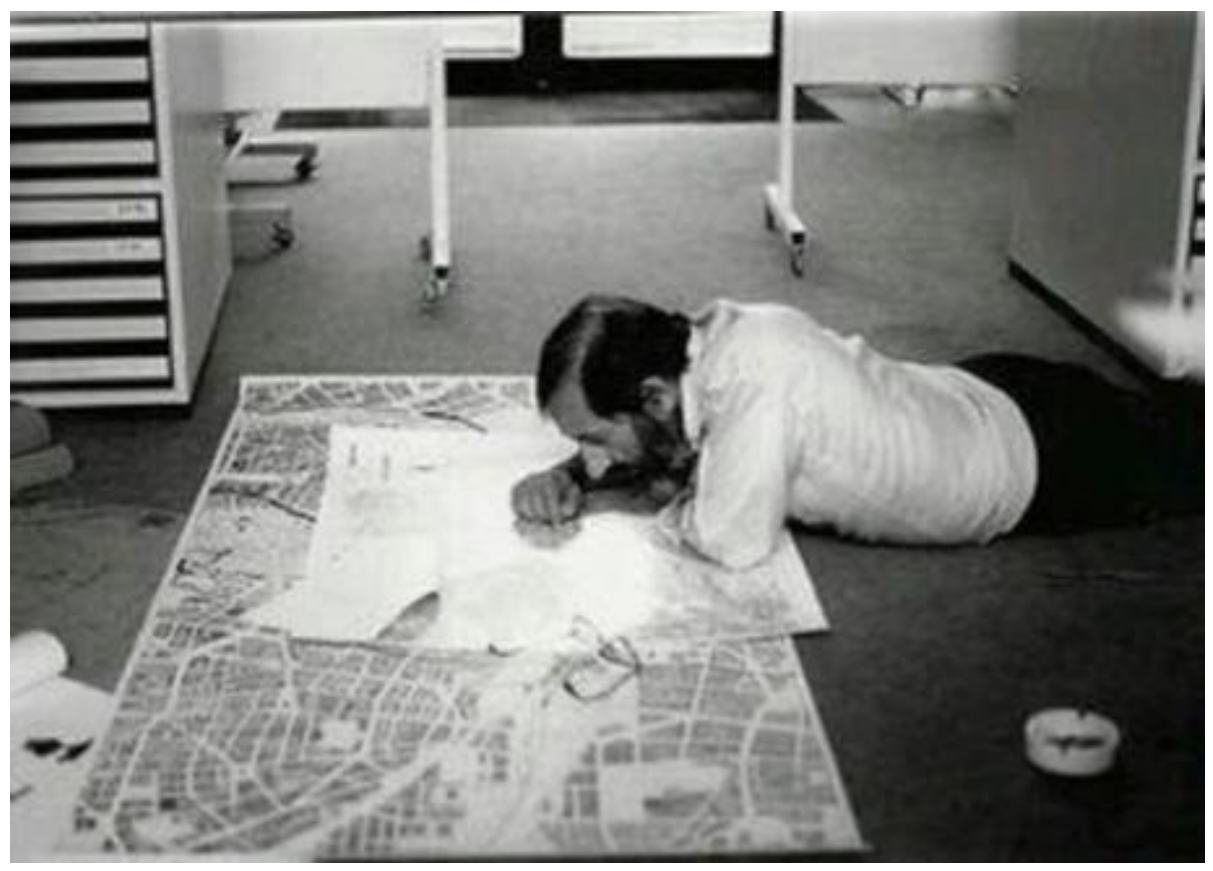

Alvaro Siza ante un proyecto

El sentido de estas acciones Fast-Arq ha sido apoyar el aprendizaje de proyectos como proceso de investigación desde la necesidad de guiar las intenciones y la creatividad, mediante la gestión de la información, el trabajo en colaboración con responsabilidades compartidas y la integración y convergencia ordenada de conocimientos de otras áreas y factores culturales. En este tiempo indómito, la propagación de discursos de estructura débil, deja en evidencia, incluso, la eficacia de la técnica. Por eso, es apropiado defender como sea, los fundamentos del proyecto desde la idea. Desde la existencia de algunos objetivos, casi siempre, muy pocos en las grandes obras, que pueden llegar a materializarse en la forma.

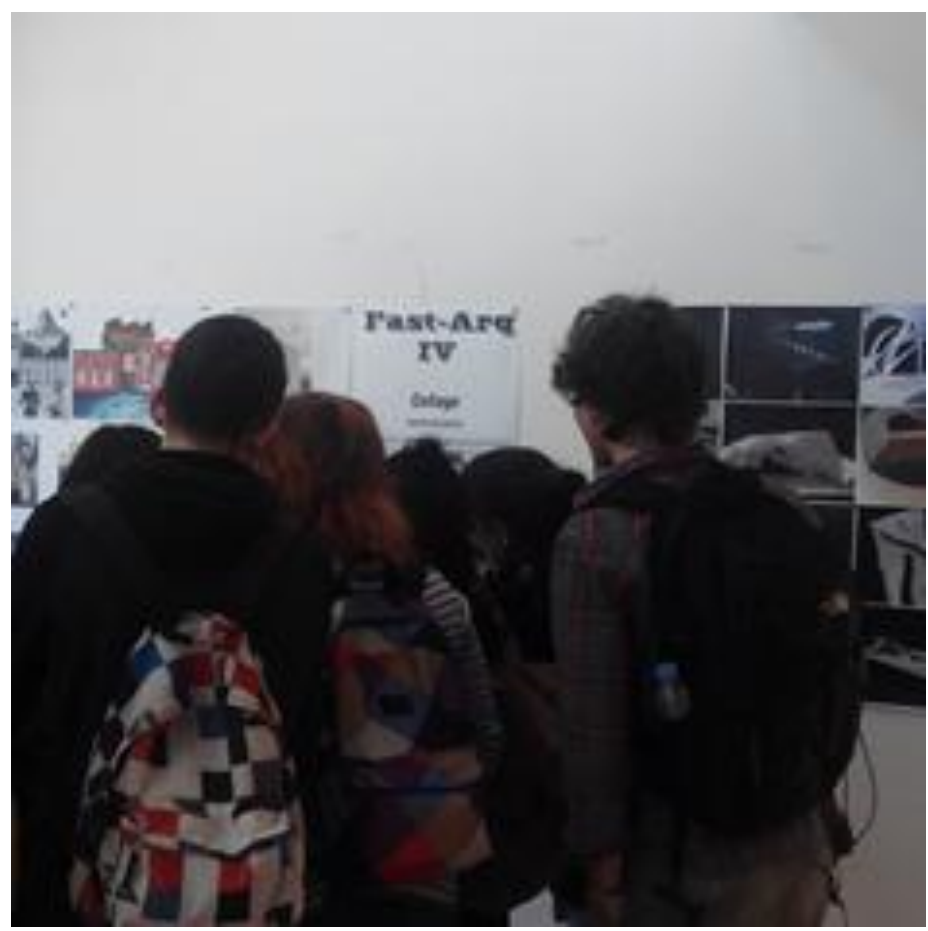


"...la revolución de lo ligero tiene dos filos. Pues la libertad individualista por poner fin a los vículos indestructibles, trae consigo la sensación de inseguridad, de incertidumbre sobre el futuro, de miedo a la expulsión. La fragilidad de los lazos y la facilidad actual para las desvinculaciones traen consigo unas veces las delicias de la renovación, otras la pesadilla de quedar colgados, abandonados, solos...son tiempos de saber instrumental" (Lipotevsky, 2016, p. 322, 338).

\section{Bibliografía}

ARIAS MADERO, J. (2016). La construcción del sueño. Poética surrealista en la arquitectura de Rem Koolhaas. Tesis Doctoral Departamento de Teoría de la Arquitectura y Proyectos arquitectónicos. E.T.S.A. Valladolid, pg. 37.

CORTÉS, J. A. (2003). Nueva Consistencia. Valladolid, Universidad de Valladolid, p.23.

DE MOLINA, S. (2016). Hambre de arquitectura. Madrid, Ed. Asimétricas, p. 58.

LIPOVETSKY, G. (2016). De la ligereza. Barcelona, Ed. Anagrama, pp. 86, 87.

MARÍAS, J. (2005). Donde todo ha sucedido. Al salir del cine. Barcelona, Galaxia Gutemberg, p.28.

MARTí ARIS, C. (2005). La cimbra y el arco. Arne Jacobsen. Arquitectura de lo inmanente. Barcelona, Fundación Caja de Arquitectos.. P. 111.

OMA, KOOLHAAS, R. and MAU, B. (1995). S.M.L.XL. 010 Publishers, p. 286.

SAINT-EXUPERY, A. (1989). El principito, Barcelona, Emece Ed., p.9,10. 